DOI: https://doi.org/10.47405/mjssh.v5i2.379

\begin{tabular}{|c|c|}
\hline 1. 1.54 & Malaysian Journal of Social Sciences and Humanities (MJSSH) \\
\hline $\begin{array}{c}\text { Malaysian Journal of } \\
\text { solal sciences and }\end{array}$ & Volume 5, Issue 2, February 2020 \\
\hline (MJ-SSH) & e-ISSN : 2504-8562 \\
\hline & $\begin{array}{l}\text { Journal home page: } \\
\text { www.msocialsciences.com }\end{array}$ \\
\hline
\end{tabular}

\title{
Gender dan Penggunaan Sumber-Sumber Sejarah
}

\author{
M. Kaviza ${ }^{1}$ \\ 1Pusat Pengajian Pendidikan dan Bahasa Moden, Universiti Utara Malaysia (UUM) \\ Correspondence: M. Kaviza (kavizakaviza@yahoo.com)
}

\begin{abstract}
Abstrak
Kajian ini bertujuan untuk mengenal pasti tahap pengetahuan, kemahiran dan sikap terhadap penggunaan sumber-sumber sejarah berdasarkan gender. Kajian ini berbentuk tinjauan dengan menggunakan soal selidik yang telah disahkan oleh pakar penilai dan mempunyai nilai kebolehpercayaan yang baik. Teknik persampelan rawak mudah telah digunakan dalam kajian ini. Data kajian ini telah dianalisis secara deskriptif dan inferensi iaitu ujian-t sampel tak bersandar dan ujian MANOVA. Hasil dapatan kajian ini menunjukkan bahawa pengetahuan, kemahiran dan sikap terhadap penggunaan sumber-sumber sejarah berada pada tahap sederhana, di samping murid perempuan melaporkan min pengetahuan, kemahiran dan sikap terhadap penggunaan sumber-sumber sejarah yang lebih tinggi berbanding dengan murid lelaki. Selain itu, gender didapati tidak mempengaruhi pengetahuan, kemahiran dan sikap terhadap penggunaan sumber-sumber sejarah secara signifikan dalam kajian ini. Implikasi kajian ini dapat membantu guru-guru sejarah untuk merancang aktiviti pengajaran dan pembelajaran sejarah yang lebih menarik dengan menggunakan sumber-sumber sejarah di dalam kelas.
\end{abstract}

Kata kunci: sumber-sumber sejarah, gender, pengetahuan, kemahiran, sikap, mata pelajaran sejarah

\section{Gender and Historical Sources Use}

\begin{abstract}
The purpose of this study is to examine the level of knowledge, skill and attitude in historical sources use. The design of this study is a survey method and using questionnaire as research instruments which has to verified by the content experts and have a good reliability value. Simple random sampling techniques have been used in this study. The data in this study were analysed descriptively and inferential statistics such as independent sample t-test and MANOVA test. The findings of this study indicate that the knowledge, skill and attitude in historical sources use at a moderate level, as well as the findings also indicate that the female students show higher knowledge, skill and attitude compared to male students. In addition, gender are reported not significantly influenced the knowledge, skills and attitude in historical sources use in this study. Therefore, the findings of this study can help the history teacher to plan more interesting and meaningful teaching and learning activities using historical sources in the classroom.
\end{abstract}

Keywords: historical sources, gender, knowledge, skill, attitude, history subject 


\section{Pengenalan}

Mata pelajaran sejarah merupakan mata pelajaran teras dalam Kurikulum Standard Sekolah Menengah (KSSM) yang dilaksanakan pada tahun 2017 untuk mencapai matlamat memberi kefahaman mengenai masyarakat, negara Malaysia dan dunia dengan memupuk dan memperkukuh identiti diri serta semangat setia negara sebagai warganegara Malaysia (Pusat Perkembangan Kurikulum (PPK), 2015). Sehubungan itu, murid perlu dipupuk dengan kemahiran berfikir yang kritis dan kreatif bagi memastikan matlamat kurikulum sejarah dapat dicapai dengan lebih baik dan telah menyarankan kepada keperluan penggunaan sumber-sumber sejarah yang berupaya untuk meningkatkan daya pemikiran kognitif aras tinggi. Sumber-sumber sejarah telah ditakrifkan sebagai bahan-bahan berbentuk primer dan sekunder yang menyediakan maklumat tentang sesuatu peristiwa sejarah yang telah berlaku. Antara sumber-sumber sejarah yang dapat digunakan dalam proses pembelajaran ialah catatan, laporan, surat, laporan harian, dokumen, rekod, majalah, enskliopedia, buku sejarah lama, artikel dan sebagainya yang boleh dimuat turun daripada portal dan laman web (Zell, 2020; Suntharalingam, 1985; Hazri Jamil, 2003; Brown \& Dotson, 2007; Johansson, 2017).

Oleh kerana terdapat jurang yang signifikan dan meningkat dalam keberhasilan murid dalam sistem pendidikan Malaysia dari segi gender iaitu murid perempuan tekal mengatasi murid lelaki dalam prestasi akademik seperti yang telah diperjelaskan dalam Pelan Pembangunan Pendidikan Malaysia 2013-2025 (Kementerian Pendidikan Malaysia [KPM], 2010), maka penglibatan semua murid yang menyeluruh tanpa merentasi gender dalam proses pengajaran dan pembelajaran diperlukan. Hal ini kerana murid-murid perlu diberikan peluang yang sama rata tanpa mengira perbezaan gender dalam menguasai hasil pembelajaran yang dihasratkan (Severiens \& Dam, 1998; Crombie, Pyke, Silverthorn, Jones, \& Piccinin, 2003; Lawrenz, 1987). Sungguhpun begitu, isu-su berkaitan dengan gender murid dalam pencapaian terhadap proses pembelajaran banyak dibicarakan dan dilaporkan dalam kajiankajian lepas seperti kajian Zuraidah Ismail, Mohd Ali Samsudin dan Ahmad Nurulazam Mohd Zain (2005), kajian Tamby Subahan Mohd Meerah (1999), kajian Hanita Mohd Yusoff dan Norzaini Azman (2018) yang telah menyuarakan kepada keperluan keprihatian keseimbangan pelaksanaan proses pengajaran dan pembelajaran di dalam kelas.

\section{Pernyataan Masalah}

Adalah tidak disangkal bahawa mata pelajaran sejarah merupakan suatu disiplin ilmu yang menggalakkan penerokaan terhadap kebenaran sesuatu peristiwa sejarah dan menjadikan murid-murid memainkan peranan sebagai seorang ahli sejarah yang professional di dalam kelas (Padilha, Bellaguardo, Nelson, Maia \& Costa, 2017; Cowgill II \& Waring, 2017; Dutt-Doner, 2015; Hover, Hicks \& Dack, 2016). Justeru, penggunaan sumber-sumber sejarah dalam proses pentafsiran merupakan suatu perkara yang tidak dapat dielakkan lagi. Sungguhpun begitu, penggunaan buku teks sepenuhnya di dalam kelas telah menyebabkan murid-murid merasakan proses pembelajaran sejarah membosankan dan tidak menarik serta telah mewujudkan persepsi yang berbeza-beza (Barton \& Levistik, 2003; Fitzgerald, 2009). Justeru, pelaksanaan pembelajaran berasaskan penggunaan sumbersumber sejarah kini semakin diberi perhatian oleh para pendidik dalam bidang pendidikan sejarah selaras dengan perkembangan pembelajaran abad ke-21 yang memfokuskan kepada startegi pembelajaran berpusatkan murid (Getman-Eraso \& Culkin, 2017; Reisman \& Fogo, 2016; Nokes, Doles \& Hacker, 2007; Reisman, 2012). Keadaan ini telah menimbulkan suatu keperluan kepada pengkaji kajian ini untuk meninjau sejauh mana persepsi murid terhadap penggunaan sumber-sumber sejarah berdasarkan gender. Hal ini kerana persepsi murid terhadap penggunaan sumber-sumber sejarah berdasarkan gender masih belum diketahui lagi walaupun dalam satu kajian yang dijalankan oleh Nokes (2014) telah membuktikan bahawa murid beraliran biasa didapati mempamerkan persepsi terhadap penggunaan sumber-sumber sejarah yang lebih positif dan tinggi berbanding dengan murid beraliran khas yang telah menimbulkan satu keperluan untuk menjalankan kajian ini. Maka, secara umumnya, kajian ini adalah bertujuan untuk mengenal pasti tahap penggunaan sumber-sumber sejarah berdasarkan gender. 


\section{Objektif Kajian}

Objektif kajian ini adalah seperti berikut:

i. Mengenal pasti tahap penggunaan sumber-sumber sejarah berdasarkan gender

ii. Mengenal pasti tahap pengetahuan, kemahiran dan sikap terhadap penggunaan sumbersumber sejarah berdasarkan gender

iii. Menentukan sama ada terdapat perbezaan min penggunaan sumber-sumber sejarah berdasarkan gender

iv. Menentukan sama ada terdapat perbezaan min pengetahuan, kemahiran dan sikap terhadap penggunaan sumber-sumber sejarah berdasarkan gender.

\section{Soalan Kajian}

Soalan kajian ini adalah seperti berikut:

i. Apakah tahap penggunaan sumber-sumber sejarah berdasarkan gender?

ii. Apakah tahap pengetahuan, kemahiran dan sikap terhadap penggunaan sumber-sumber sejarah berdasarkan gender?

iii. Adakah terdapat perbezaan min penggunaan sumber-sumber sejarah berdasarkan gender?

iv. Adakah terdapat perbezaan min pengetahuan, kemahiran dan sikap terhadap penggunaan sumber-sumber sejarah berdasarkan gender?

\section{Hipotesis Kajian}

Bagi menjawab soalan kajian 3 dan 4, maka dua hipotesis kajian telah dibentuk untuk diuji pada aras kesignifikan $p=0.05$ adalah seperti berikut:

$\mathrm{H}_{\mathrm{o} 1}$ : Tidak terdapat perbezaan min penggunaan sumber-sumber sejarah berdasarkan gender.

$\mathrm{H}_{\mathrm{o} 2}$ : Tidak terdapat perbezaan min pengetahuan, kemahiran dan sikap terhadap penggunaan sumber-sumber sejarah berdasarkan gender.

\section{Metod Kajian}

Kajian ini merupakan kajian berbentuk tinjauan dengan menggunakan soal selidik yang melibatkan murid tingkatan empat iaitu seramai 240 orang murid lelaki dan seramai 281 orang murid perempuan yang ditentukan berdasarkan teknik persampelan rawak. Soal selidik tersebut telah melalui proses kesahan kandungan dan konstruk dan mempunyai nilai kebolehpercayaan yang baik iaitu 0.86 dan boleh diterima bagi tujuan kajian ini (Nunnally, 1978). Data statistik deskriptif dan inferensi iaitu ujian-t sampel tak bersandar dan ujian MANOVA dalam kajian ini telah dianalisis dengan menggunakan perisian pengaturcaraan IBM SPSS Statistics versi 24. Interpretasi tahap min dalam kajian ini adalah berdasarkan kajian Nik Mohd Rahimi, (2004) seperti yang ditunjukkan pada Jadual 1.

Jadual 1: Interpretasi Tahap Min

\begin{tabular}{cc}
\hline Min & Tahap \\
\hline $5.01-7.00$ & Tinggi \\
$3.01-5.00$ & Sederhana \\
$1.00-3.00$ & Rendah \\
\hline
\end{tabular}

Sumber: Adaptasi daripada Nik Mohd Rahimi, (2004) 


\section{Dapatan Kajian}

\section{Objektif Kajian 1: Mengenal pasti tahap penggunaan sumber-sumber sejarah berdasarkan gender}

Berdasarkan Jadual 2, penggunaan sumber-sumber sejarah bagi murid lelaki $(M=4.32, S D=0.96)$ dan murid perempuan $(M=4.38, S D=0.97)$ berada pada tahap sederhana. Min penggunaan sumber-sumber sejarah adalah lebih tinggi bagi murid perempuan berbanding dengan murid lelaki. Justeru, dapat dirumuskan bahawa tahap penggunaan sumber-sumber sejarah adalah sederhana bagi murid lelaki dan murid perempuan dalam kajian ini.

Jadual 2: Penggunaan Sumber-sumber Sejarah

\begin{tabular}{lcc}
\hline & Murid Lelaki & Murid Perempuan \\
\hline Min $(M)$ & 4.32 & 4.38 \\
Sisihan piawai $(S D)$ & 0.96 & 0.97 \\
N & 240 & 281 \\
Tahap & Sederhana & Sederhana \\
\hline
\end{tabular}

\section{Objektif Kajian 2: Mengenal pasti tahap pengetahuan, kemahiran dan sikap terhadap penggunaan sumber-sumber sejarah berdasarkan gender}

Berdasarkan Jadual 2, pengetahuan terhadap penggunaan sumber-sumber sejarah bagi murid lelaki $(M=4.30, S D=1.13)$ dan murid perempuan $(M=4.36, S D=1.20)$ berada pada tahap sederhana. Selain itu, kemahiran terhadap penggunaan sumber-sumber sejarah bagi murid lelaki $(M=4.34, S D=1.16)$ dan murid perempuan $(M=4.41, S D=1.18)$ berada pada tahap sederhana. Seterusnya, sikap terhadap penggunaan sumber-sumber sejarah bagi murid lelaki $(M=4.30, S D=1.16)$ dan murid perempuan $(M=4.33, S D=1.20)$ berada pada tahap sederhana. Min pengetahuan, kemahiran dan sikap terhadap penggunaan sumber-sumber sejarah adalah lebih tinggi bagi murid perempuan berbanding dengan murid lelaki. Justeru, dapat dirumuskan bahawa tahap pengetahuan, kemahiran dan sikap terhadap penggunaan sumber-sumber sejarah adalah sederhana bagi murid lelaki dan murid perempuan dalam kajian ini.

Jadual 3: Min Pengetahuan, Kemahiran dan Sikap Terhadap Penggunaan Sumber-sumber Sejarah

\begin{tabular}{lcccccc}
\hline Konstruk & \multicolumn{3}{c}{ Murid Lelaki } & \multicolumn{3}{c}{ Murid Perempuan } \\
& $\boldsymbol{M}$ & $\boldsymbol{S D}$ & Tahap & $\boldsymbol{M}$ & $\boldsymbol{S D}$ & Tahap \\
\hline Pengetahuan & 4.30 & 1.13 & Sederhana & 4.36 & 1.20 & Sederhana \\
Kemahiran & 4.34 & 1.16 & Sederhana & 4.41 & 1.18 & Sederhana \\
Sikap & 4.30 & 1.16 & Sederhana & 4.33 & 1.20 & Sederhana \\
\hline
\end{tabular}

\section{Objektif Kajian 3: Menentukan sama ada terdapat perbezaan min penggunaan sumber-sumber sejarah berdasarkan gender}

Berdasarkan keputusan ujian Levene's yang tidak signifikan $[F=3.30, p=0.57]$ pada Jadual 4 telah menunjukkan bahawa tidak terdapat perbezaan yang signifikan bagi min penggunaan sumber-sumber sejarah $[t(519)=-0.78, p=0.44]$ berdasarkan gender. Maka, hipotesis nol $\left(\mathrm{H}_{\mathrm{ol}}\right)$ telah gagal ditolak. Justeru, dapat dirumuskan bahawa gender tidak mempengaruhi penggunaan sumber-sumber sejarah dalam kajian ini. 
DOI: https://doi.org/10.47405/mjssh.v5i2.379

Jadual 4: Ujian-t Sampel Tak Bersandar Bagi

Penggunaan Sumber-sumber Sejarah Berdasarkan Gender

Ujian-t bagi persamaan min

\begin{tabular}{|c|c|c|c|c|c|c|}
\hline $\begin{array}{c}\text { Ujian } \\
\text { Levene's }\end{array}$ & $t$ & $d t$ & $p$ & $\begin{array}{c}\text { Perbezaan } \\
\text { min }\end{array}$ & $\begin{array}{c}\text { Min } \\
\text { ralat } \\
\text { Piawai }\end{array}$ & $\begin{array}{l}99 \% \text { selang } \\
\text { keyakinan bagi } \\
\text { perbezaan }\end{array}$ \\
\hline
\end{tabular}

\begin{tabular}{|c|c|c|c|c|c|c|c|c|c|}
\hline & $F$ & Sig & & & & & & Bawah & Atas \\
\hline $\begin{array}{l}\text { Perbezaan } \\
\text { Min }\end{array}$ & 3.30 & 0.57 & -0.78 & 519 & 0.44 & -0.07 & 0.06 & -0.23 & 0.10 \\
\hline
\end{tabular}

\section{Objektif Kajian 4: Menentukan sama ada terdapat perbezaan min pengetahuan, kemahiran dan sikap terhadap penggunaan sumber-sumber sejarah berdasarkan gender}

Berdasarkan keputusan ujian Box's $M$ yang menunjukkan keputusan tidak signifikan, ujian multivariate pada Jadual 5 telah melaporkan nilai Pillai's Trace $[F(3,517)=0.28, p=0.42]$ yang menunjukkan bahawa tidak terdapat kesan gender yang signifikan bagi pengetahuan, kemahiran dan sikap terhadap penggunaan sumber-sumber sejarah. Seterusnya, walaupun nilai ujian Levene's bagi pengetahuan, kemahiran dan sikap terhadap penggunaan sumber-sumber sejarah tidak signifikan dan mematuhi syarat pengujian ujian multivariate, namun ujian kesan antara subjek pada Jadual 6 menunjukkan bahawa pengetahuan $[F(1,519)=0.41, p=0.53]$, kemahiran $[F(1,519)=0.48, p=0.49]$ dan sikap $[F(1,519)=0.10, p=0.76]$ terhadap penggunaan sumber-sumber sejarah adalah tidak signifikan. Maka, hipotesis $\mathrm{Ho}_{1}$ telah gagal ditolak. Justeru, dapat dirumuskan bahawa gender tidak mempengaruhi pengetahuan, kemahiran dan sikap terhadap penggunaan sumber-sumber sejarah dalam kajian ini.

Jadual 5: Ujian Multivariate

\begin{tabular}{|c|c|c|c|c|c|c|c|}
\hline Kesan & & Nilai & $F$ & $\begin{array}{l}\text { Hipotesis } \\
\qquad d f\end{array}$ & $\begin{array}{c}\text { Ralat } \\
\quad d f\end{array}$ & Sig. & $\begin{array}{c}\text { Separa } \\
\text { Eta } \\
\text { Kuasa } \\
\text { Dua }\end{array}$ \\
\hline \multirow{4}{*}{ Pintasan } & Pillai's Trace & 0.94 & 2654.87 & 3.00 & 517.00 & 0.00 & 0.94 \\
\hline & Wilks' Lambda & 0.06 & 2654.87 & 3.00 & 517.00 & 0.00 & 0.94 \\
\hline & Hotelling's Trace & 15.41 & 2654.87 & 3.00 & 517.00 & 0.00 & 0.94 \\
\hline & Roy's Largest Root & 15.41 & 2654.87 & 3.00 & 517.00 & 0.00 & 0.94 \\
\hline \multirow[t]{4}{*}{ Gender } & Pillai's Trace & 0.00 & 0.28 & 3.00 & 517.00 & 0.84 & 0.00 \\
\hline & Wilks’ Lambda & 0.99 & 0.28 & 3.00 & 517.00 & 0.84 & 0.00 \\
\hline & Hotelling's Trace & 0.00 & 0.28 & 3.00 & 517.00 & 0.84 & 0.00 \\
\hline & Roy's Largest Root & 0.00 & 0.28 & 3.00 & 517.00 & 0.84 & 0.00 \\
\hline
\end{tabular}

Jadual 6: Ujian Kesan Antara Subjek

\begin{tabular}{llcccccc}
\hline Sumber & $\begin{array}{c}\text { Variabel } \\
\text { bersandar }\end{array}$ & $\begin{array}{c}\text { Jumlah } \\
\text { Kuasa dua } \\
\text { Jenis III }\end{array}$ & $\begin{array}{c}\text { Darjah } \\
\text { kebebasan }\end{array}$ & $\begin{array}{c}\text { Kuasa } \\
\text { Dua } \\
\text { Min }\end{array}$ & F & Sig. & $\begin{array}{c}\text { Separa } \\
\text { Eta } \\
\text { Kuasa } \\
\text { Dua }\end{array}$ \\
\hline Model yang & Pengetahuan & 0.55 & 1 & 0.55 & 0.41 & 0.53 & 0.00 \\
diperbetulkan & $\begin{array}{l}\text { Kemahiran } \\
\text { Sikap }\end{array}$ & 0.66 & 1 & 0.66 & 0.48 & 0.49 & 0.00 \\
\hline Pintasan & Pengetahuan & 9702.74 & 1 & 0.14 & 0.10 & 0.75 & 0.00 \\
\hline
\end{tabular}


Malaysian Journal of Social Sciences and Humanities (MJSSH), Volume 5, Issue 2, (page 107 - 115), 2020

DOI: https://doi.org/10.47405/mjssh.v5i2.379

\begin{tabular}{llcccccc}
\hline & Kemahiran & 9928.47 & 1 & 9928.47 & 7242.27 & 0.00 & 0.93 \\
& Sikap & 9644.94 & 1 & 9644.94 & 6882.18 & 0.00 & 0.93 \\
\hline Gender & Pengetahuan & 0.55 & 1 & 0.55 & 0.41 & 0.53 & 0.00 \\
& Kemahiran & 0.66 & 1 & 0.66 & 0.48 & 0.49 & 0.00 \\
& Sikap & 0.14 & 1 & 0.14 & 0.10 & 0.75 & 0.00 \\
\hline Ralat & Pengetahuan & 707.47 & 519 & 1.36 & & & \\
& Kemahiran & 711.50 & 519 & 1.37 & & & \\
& Sikap & 727.35 & 519 & 1.40 & & & \\
\hline Jumlah & Pengetahuan & 10482.87 & 521 & & & & \\
& Kemahiran & 10715.29 & 521 & & & & \\
& Sikap & 10438.33 & 521 & & & & \\
\hline \multirow{2}{*}{ Jumlah yang } & Pengetahuan & 708.02 & 520 & & & & \\
Diperbetulkan & Kemahiran & 712.16 & 520 & & & & \\
& Sikap & 727.49 & 520 & & & &
\end{tabular}

${ }^{\mathrm{a}}$. R Squard $=0.00$ (Adjusted R Squared $\left.=-0.00\right)$

b. $\mathrm{R}$ Squard $=0.00$ (Adjusted R Squared $=-0.00$ )

'. R Squard $=0.00$ (Adjusted R Squared $=-0.00)$

\section{Perbincangan Kajian}

Dapatan kajian ini yang menunjukkan bahawa tahap penggunaan sumber-sumber sejarah adalah sederhana bagi murid lelaki dan perempuan secara keseluruhannya walaupun murid perempuan melaporkan persepsi yang lebih tinggi berbanding dengan murid lelaki adalah konsisten dengan dapatan kajian Cowgill dan Waring (2017), kajian Vansledright dan Kelly, (1998) dan Tally dan Goldenberg, (2005), kajian Cameron, Meter dan Long, (2016) kajian Getman-Eraso dan Culkin, (2017 dan kajian Langan, (2015) yang mendapati bahawa penggunaan sumber-sumber sejarah masih kurang dalam kalangan murid yang telah menimbulkan tanggapan negatif terhadap sumber-sumber sejarah sebagai sesuatu yang sukar dan rumit. Namun begitu, pengetahuan, kemahiran dan sikap yang berada pada tahap sederhana dan murid perempuan yang mempamerkan persepsi yang lebih tinggi berbanding dengan murid lelaki dalam kajian ini adalah selaras dengan dapatan kajian Nokes (2014) yang mendapati bahawa murid beraliran biasa telah mempamerkan persepsi pencapaian yang tinggi berbanding dengan murid beraliran khas dalam aktiviti pembelajaran berteraskan penggunaan sumber teks dan kajian Hartono, Nurul, Sumarno dan Rully, (2019) pula yang telah melaporkan bahawa penglibatan murid perempuan dalam proses pembelajaran mata pelajaran sejarah adalah lebih tinggi berbanding dengan murid lelaki yang telah menyokong dapatan kajian ini secara tidak langsung. Hal ini kerana perbezaan murid dari aspek intra dan inter didapati mempengaruhi persepsi dan perlakuan antara murid lelaki dan perempuan yang menjurus kepada proses pembelajaran yang maksimum (Atan Long, 1978; Maznah Ismail \& Yoong, 1995; Olubelu dan Abebanjo, 2019). Justeru, penggunaan sumber-sumber sejarah melalui pelaksanaan proses pengkajian sejarah dalam kurikulum mata pelajaran sejarah adalah diakui berpotensi untuk meningkatkan kebolehan murid dan melengkapkan diri mereka dengan pelbagai kemahiran belajar sejarah secara berterusan (Nokes et al, 2007; Apaolaza-Liorente \& Arguero, 2019; Cutrara, 2019; Barton, 2018; Wahyu, 2019; Hill; \& Fitzpatrick, 2019; Fogo, Reisman \& Breakstone, 2019). Hal ini kerana murid-murid dapat melibatkan diri dalam proses pembelajaran sejarah secara autentik dengan mencari dan meneroka bukti sejarah yang relevan untuk membuat suatu kesimpulan yang munasabah dan rasional (Scheiner-Fisher, 2014; Reisman, 2012; Nokes, 2014; Suh, 2013; Patterson, Lucas \& Kithinji, 2012).

Tambahan pula, dapatan kajian ini yang telah melaporkan bahawa tidak terdapat perbezaan min penggunaan sumber-sumber sejarah dari aspek pengetahuan, kemahiran dan sikap yang signifikan berdasarkan gender adalah sealiran dengan dapatan kajian Mohd Ali Samsudin, Ahmad Nurulazam Md Zain, Sayedh Mahbooheh Jamali dan Nader Ale Ibrahim (2017), dan kajian Mohd Zuri Ghani, Nik Rusila Nik Yaacob, Azman Che Ahmad, Rahimi Che Aman dan Zainuddin Mat Isa (2010) yang telah melaporkan bahawa gender tidak mempengaruhi pencapaian dalam pelaksanaan projek STEM dan personaliti kestabilan emosi dalam kalangan murid. Sungguhpun begitu, dapatan kajian ini didapati bertentangan dengan dapatan kajian-kajian lepas yang telah membuktikan bahawa gender 
mempengaruhi persepi, pencapaian, kebolehan dan menjadi faktor penyumbang kepada keberkesanan proses pembelajaran dalam kalangan murid (Hanita Mohd Yusoff \& Norzaini Azman, 2020; Kilia \& Saglam, 2010; Chang, Zamri Mohamad \& Hamidah Yamat, 2013; Zamri Mahamod \& Noor Syazwani Rani, 2013; Haslina Hassan, Ramlah Mailok \& Mashitah Hashim, 2019; Tang, Zarinah \& Rumaya, 2020; Glowka, 2014; Wehrwein, Lujan \& Dicarlo, 2007; Thomas \& Allen, 2006; Poh, \& Mellissa, 2008; Jackman \& Morrain-Webb, 2019; Abdul \& Mariyam, 2017; Ayesha, Raneem, Nasser $\&$ Nada, 2013). Justeru, gender dibuktikan memberikan persepsi dan tanggapan yang berbeza-beza dan perlu diberikan perhatian dalam proses pembelajaran.

\section{Kesimpulan}

Kesimpulannya, kajian ini telah mendapati bahawa pengetahuan, kemahiran dan sikap terhadap penggunaan sumber-sumber sejarah bagi murid lelaki dan murid perempuan berada pada tahap sederhana. Implikasi kajian ini telah menyediakan sumber maklumat kepada para pendidik dalam bidang pendidikan sejarah bahawa gender bukannya faktor penghalang yang mempengaruhi penggunaan sumber-sumber sejarah. Justeru, semua pihak perlu menyedari tentang kepentingan penerokaan dan penggunaan sumber-sumber sejarah sebagai bahan pembelajaran sejarah yang mampu mengupayakan perkembangan dan pengamalan aplikasi kemahiran berfikir aras tinggi dalam kalangan murid seperti yang telah digariskan dalam Pelan Pembangunan Pendidikan Malaysia 2013-2025.

\section{Rujukan}

Abdul, G.A., \& Mariyam, S.A. (2017). Gender differences and its impact on students performance: A socio-linguistic analysis. Global Journal of Management, Social Sciences and Humanities, 3(2), $352-372$.

Apaolaza-Lioerente, D., \& Arguero, B.E. (2019). Doing History: History sources abd active methodologies to foster historical thinking in secondary school. ENSAYOS, Revista de la Faculated de Education de Albacete, 34(1), 29-40.

Atan Long. Psikologi Pendidikan. Kuala Lumpur: Dewan Bahasa dan Pustaka.

Ayesha, N., Raneem, O.S, Nasser, A.H \& Nada, A. (2013). Gender differences in learning style and academic performances of medical students in Saudi Arabia. Medical Teacher, 35, 78-82.

Barton, K.C. (2018). Historical sources in the classroom: Purpose and use. HSSE Online, 7(2), 1-11.

Barton, K.C., \& Levistik, L.S. (2003). Why don't more history teachers engage students in interpretation? Social Education, 67(6), 358-358.

Brown, C.A., \& Dotson, K. (2007). A Case Study Using Digital Primary Source Documents. TechTrends, 51(3), 30-37.

Cameron, C., Meter, P.V., \& Long, V.A. (2016). The Effects of Instruction on students' Generation of Self-Questions When Reading Multiple Documents. The Journal of Experimental Education, 118.

Chang, O.S., Zamri Mohamad \& Hamidah Yamat (2013). Faktor jantina, kaum, aliran kelas dan hubungannya dengan kecerdasan emosi murid dalam mempelajari Bahasa Melayu. Jurnal Pendidikan Bahasa Melayu, 3(1), 12-23.

Cowgill II, D.A., \& Waring, S.M. (2017). Historical Thinking: An Evaluation of Student and Teacher Ability to Analyze Sources. Journal of Social Studies Education Research. 8(1), 115-145.

Crombie, G., Pyke, S.W., Silverthorn, N., Jones, A., \& Piccinin, S. (2003). Students' perceptions of their classroom participation and instructor as a function of gender and context. The Journal of Higher Education, 74(1), 51-76.

Cutrara, S. (2019). Tge subjectivity of archives: Learning from, with and resisting archives and archival sources in the teaching and learning history. Historical Encounters: A Journal of Historical Consciousness, historical cultures and history education, 6(1), 117-132.

Dutt-Doner, K.M. (2015). Increasing Pre-service Teachers' Capacity to Utilize and Implement Primary Source Instruction in the Elementary Classroom. National Teacher Education Journal, 8(1), 13-24. 
Fitzgerald, J.C. (2009). Textbooks and Primary Source Analysis. Social Studies Research and Practice, 4(8), 37-43.

Fogo, B., Reisman, A \& Breakstone, J. (2019). Teacher adaptation of document-based history curricula: results of the Reading Like a Historian curriculum-use survey. Journal of Curriculum Studies, 1-22.

Getman-Eraso, J., \& Culkin, K. (2017). Close Reading: Engaging and Empowering History Students through Document Analysis on e-Portfolio. International Journal of e-Portfolio, 7(1), 29-42.

Glowka, D. (2014). The impact of gender on attaitment in learning English as a foreign language. Studies Journal in Second Language Learning and Technology, 4(4), 617-635.

Hanita Mohd Yusoff \& Norzaini Azman (2018). Pencapaian akademik murid lelaki dan perempuan: Peranan sokongan pembelajaran dan keterlibatan murid. Malaysian Journal of Learning and Instruction, 15(2), 257-287.

Hanita Mohd Yusoff \& Nurzaini Azman (2020). Perbezaan gender dalam pencapaian murid: Kaitannya dengan keterlibatan murid dan sokongan pembelajaran. Southest Asia Psychology Journal, 10, 96-110.

Hartono, F.P., Nurul U., Sumarno, Rully, P.N.P. (2019). The level of student engagement based on gender and grade on history subject of senior high school students in Jember regency. International Journal of Scientific \& Technology Research, 8(8), 1-16.

Haslina Hassan, Ramlah Mailok, \& Mashitah Hashim. (2019). Gender and game genre differences in playing online games. Journal of ICT in Education, 6, 1-15.

Hazri Jamil. (2003). Teknik mengajar Sejarah. Pahang: PTS Publications \& Distributors Sdn Bhd.

Hill, E.W., \& Fitzpatrick, C. (2019). Impact of primary sources activities on student understanding, engagement and interest. Proceedings of Studies in teaching 2019 Research Digest: Action Research Projects, Winston-Salem, 27 Jun 2019.

Hover, S.V., Hicks, D., \& Dack, H. (2016). From Source to Evidence? Teachers' Use of Historical Sources in Their Classrooms. The Social studies, 107(6), 209-217.

Jackman, W.M \& Morrain-Webb, J. (2019). Exploring gender differences in achievement through student voice: critical insight and analyses. Cogent, Education, 6, 1-13.

Johansson, P. (2017). Learning study as a clinical research practice to generate knowledge about the learning of historical primary source analysis. Educational Action Research, 25(1), 167-181.

Kilia, D \& Saglam, N. (2010). Investigating the effects of gender and school type on students learning orientation. Procedia Social and Behaviorial Science, 12, 3378-3382.

Langan, E. (2015). Using Multiple-Perspective Primary Sources to Enhance Pre-service Teachers' Understandings. Teacher Education and Practice, 28(4), 617-626.

Lawrenz, F. (1987). Gender effects for student perception of the classroom psychosocial environment. Journal of Research in Science Teaching, 24(8), 689-697.

Maznah Ismail \& Yoong, S. (1995). Kajian terhadap pendekatan pembelajaran pelajar. Jurnal Pendidik dan Pendidikan, 14, 11-18,

Mohd Ali Samsudin, Ahmad Nurulazam Md Zain, Sayedh Mahbooheh Jamali \& Nader Ale Ibrahim. (2017). Physics achievement in STEM Project based Learning (PjBL): A gender study. Asia Pacific Journal of Educators and Education, 32, 21-28.

Mohd Zuri Ghani, Nik Rusila Nik Yaacob, Azman Che Ahmad, Rahimi Che Aman \& Zainuddin Mat Isa. (2010). Perbezaan personality kestabilan emosi dalam kalangan pelajar pintar ceerdas akademik (PCA) Berdasarkan jantina dan jenis sekolah. Asia Pacific Journal of Educator and Education, 25, 153-167.

Nik Mohd Rahimi Nik Yusoff. (2004). Kemahiran mendengar Bahasa Arab: Satu Kajian di Sekolah Menengah Kerajaan Negeri. Tesis Kedoktoran Universiti Kebangsaan Malaysia, Bangi.

Nokes, J.D. (2014). Elementary students' Roles and Epsitemic Stances during Document Based History Lessons. Theory \& Research in Social Education, 42, 375-413.

Nokes, J.D., Dole, J.A., \& Hacker, D.J. (2007). Teaching High School Students to Use Heuristics While Reading Historical Texts. Journal of Educational Psychology, 4(9), 1-13.

Nunnally, J.C. (1978). Psychometrie Theory $\left(2^{\text {nd }}\right.$ Ed). New York: McGraw Hill.

Olubelu, A., \& Abebanjo, A. (2019). Learning styles and gender effects on secondary scholls students learning outcomes in Ijebu-Ode Community, Ogun State, Negeria. KIU Journal Humanities, 4(4), 155-169. 
Padilha, M.I., Bellaguardo, M.L.D.R., Nelson, S., Maia, A.R.C., \& Costa, R. (2017). The use of sources in historical research. Reflection, 1-10.

Patterson, N.C., Lucas, A.G., \& Kithinji, M. (2012). Higher Order Thinking in Social Studies: An analysis of Primary Source Document Use. Social studies Research and Practice, 7(2), 68-85.

Poh, B.T \& Mellissa, N.L.Y. A (2008). Kesan faktor jantina, etnik dan gaya kognitif ke atas pencapaian pengajian am. Jurnal Pendidik dan Pendidikan, 23, 123-140.

Pusat Perkembangan Kurikulum. (2015) Dokumen Standard Kurikulum dan Pentaksiran Mata Pelajaran Sejarah Tingkatan Satu. Putrajaya: Kementerian Pendidikan Malaysia.

Reisman, A. (2012). The "Document-Based Lesson": Bringing Disciplinary inquiry into high school history classrooms with adolescent struggling readers. Journal of Curriculum Studies, 44(2), 233264.

Reisman, A., \& Fogo, B. (2016). Contributions of Educative document based curricular materials to quality of historical instruction. Teaching and Teacher Education, 59, 191-202.

Scheiner-Fisher, C. (2014). Using SOURCES to allow digital natives to explore the Lewis and Clark Expedition. Middle School Journal, 45(4), 3-12.

Severiens, S., \& Dam, G.T. (1998). Gender and learning: Comparing two theories. Higher Education, 35(8), 329-350.

Suh, Y. (2013). Past Looking: Using Arts as Historical Evidence in Teaching History. Social Studies Research and Practice, 8(1), 135-159.

Suntharalingam. (1985). Pengenalan Kepada Sejarah. Kuala Lumpur: Marican \& Sons (M). Sdn Bhd

Tally, B., \& Goldenberg, L.B. (2005). Fostering Historical Thinking with Digitized Primary Resources. Journal of Research on Technology in Education, 38(1), 1-21

Tamby Subahan Mohd Meerah. (1999). Dampak penyelidikan pembelajaran sains terhadap peradaban kurikulum. Bangi: Universiti Kebangsaan Malaysia.

Tang, L.F., Zarinah, A., \& Rumaya, J. (2020). Sex differences in intellectual ability among preschool children in Putrajaya. International Journal of Education, Psychology and Counseling, 5(34), 4057.

Thomas, T \& Allen, A. (2006). Gender differences in students perceptions of Information Technology as a career. Journal of Information Technology Education, 5, 1-15.

VanSledright, B.A., \& Kelly, C. (1998). Reading American History: The Influence of Multiple Sources on Six Fifth Graders. The Elementary School Journal, 98(3), 239-265.

Wehrwein, E.A, Lujan, H.L \& Dicarlo, S.E. (2007). Gender differences in learning style perferences among undergraduate physiology students. American Physiological Society, 31, 153-157.

Zamri Mahamod, \& Noor Syazwani Rani (2013). Tahap kemahiran generik pelajar dalam pembelajaran kesusasteraan melayu. Jurnal Teknologi, 64(1), 17-23.

Zell, M.I. (1979). Fifteenth and sixteenth century wills as historical sources. Archives, 11(62), 67.

Zurida Haji Ismail, Mohd Ali Samsudin \& Ahmad Nurulazam Mohd Zain. (2005). Kesan pengajaran konstektual ke atas pencapaian pelajar dalam fizik. Jurnal Pendidik dan Pendidikan, 20, 43-52.

Wahyu, D.S. (2019). Learning activities from learning resources: Pemartabatan dan pemaknaan situs sejarah kawasan alun-alun merdeka Kota Malang. Jurnal Pendidikan Sejarah Indonesia, 2(1), 4963. 